\title{
Enhanced Ion Signals in Desorption Electrospray Ionization Using Surfactant Spray Solutions
}

\author{
Abraham Badu-Tawiah and R. Graham Cooks \\ Chemistry Department, Purdue University, West Lafayette, Indiana, USA
}

Solvent optimization is an important procedure in desorption electrospray ionization (DESI) and in this study the effects of solvent surface tension are explored. Data are presented for methanol/water/surfactant solvent systems, which show increases in ion signals of more than an order of magnitude when low concentrations of surfactants are added to the standard methanol/water (1:1) spray solvent. Examples of analytes tested include food chemicals, peptides, pharmaceuticals, and drugs of abuse. The improvement in ion intensity is mainly attributed to the effect of surface tension in producing smaller spray droplets, which are shown to cover a larger surface area. Surfactant-containing spray solutions allowed extension of DESI-MS analysis to previously intractable analytes like melamine and highly hydrophobic compounds like the sudan dyes. (J Am Soc Mass Spectrom 2010, 21, 1423-1431) @ 2010 American Society for Mass Spectrometry

$\mathrm{D}$ esorption electrospray ionization (DESI) [1,2] is a widely used ambient ionization technique [3-8], which is used for surface sampling $[9,10]$, high throughput analysis [11, 12], and chemical imaging [13-17], largely because of its applicability to in situ analyte detection from unmodified surfaces. In DESI, a nebulized electrospray of high-velocity charged microdroplets is directed at a surface from which the solvent extracts analyte and carries it to the mass spectrometer in the form of secondary microdroplets. This methodology has been applied in a variety of disciplines including forensics [18, 19], environmental science [20], food science [12, 21], and pharmaceutical science [22]. With increased interest in ambient desorption mass spectrometry, the need has arisen to develop more versatile solvent systems that are applicable to a wider range of samples than is currently the case. One aspect of this effort is the use of non-aqueous spray solutions [23] and another is the addition of reagents to the spray solvent chosen to react and give ionic derivatives of the analytes of interest [24]. Both are discussed further below. In this work, we explore the special properties of spray solutions containing surfactants, in an attempt to increase the ion intensity and to learn more about the mechanisms of DESI.

Three mechanisms have been identified in DESI, all falling under the rubric of droplet pick-up. The first and best established is the droplet micro-extraction mechanism $[25,26]$. In this mechanism, initial droplets arriving at the surface form a localized and probably discontinuous liquid thin film, which dissolves analyte present on the surface. Subsequent droplet-liquid-thin-film collisions

Address reprint requests to Professor R. G. Cooks, Department of Chemistry, Purdue University, 560 Oval Drive, West Lafayette, IN 47907, USA. E-mail: cooks@purdue.edu produce secondary microdroplets containing the analyte, which are then sucked into the mass spectrometer for mass/charge analysis. A second mechanism is believed to involve gas-phase ion/molecule reactions [2]. In this case, vaporization of the analyte from the surface is followed by fast charge-transfer reactions with protonated (or other) solvent molecules or droplets to produce charged analytes, which are then transferred into the mass spectrometer for mass analysis. A third mechanism, which also seems to make a limited contribution to ion production in DESI, involves reactive ion/surface collisions [25, 27] sometimes known as chemical sputtering.

In parallel with these advances in mechanistic understanding, surface and solvent systems used in DESI have been shown to have significant effects on ion intensity and several attempts have been made to identify improved systems. It is now understood that electrically nonconducting substrates increase ion signal in DESI experiments since they preserve charges by avoiding their neutralization [2, 28]. Rough surfaces have advantages in that they more effectively retain analyte under the influence of the strong washing effect produced by the nebulized spray. It has also become clear that the analyte should be soluble $[23,25,29-31]$ in the localized liquid thin film (or simply in the spray solvent) to facilitate its transfer from the surface. A solvent optimization procedure has recently been described in which polar and non-polar solvents are advised for hydrophilic and hydrophobic analytes, respectively [23]. In particular cases, an order of magnitude signal enhancement was observed in experiments in which non-aqueous spray solvents were used for highly hydrophobic analytes, compared to the standard hydrophilic $\mathrm{CH}_{3} \mathrm{OH} / \mathrm{H}_{2} \mathrm{O}$ spray system. Chemical reactions have also been used to increase the ion intensities for certain analytes through reactive DESI experi- 
ments $[24,32,33]$. In reactive DESI, specific reagents are added to the spray solvent to react selectively with particular functional groups present in the mixture; appropriate reagents produce charged derivatives that are ionized efficiently. In the present study, we explore the possibility that a physical property of the spray solution, its surface tension, can be used as a means of improving DESI performance for both hydrophilic and hydrophobic compounds. Specifically, surfactants were added to manipulate the surface tension of the $\mathrm{CH}_{3} \mathrm{OH} / \mathrm{H}_{2} \mathrm{O}(1: 1)$ spray solvent.

Surfactant solutions employed in this study include the cyclic peptide, surfactin, as well as fluorinated alkyl sulfonamides (industrial surfactants FC-129, FC-135 and FC-171, Scheme 1). Surfactin, which adopts a characteristic horse-saddle conformation in water $[34,35]$ is an amphiphilic lipopeptide produced by various strains of Bacillus subtilis. It consists of a heptapeptide head-group, linked to a $\mathrm{C}_{12}-\mathrm{C}_{15} \beta$-hydroxy fatty acid. The industrial surfactants FC-129, FC-135, and FC-171 consist of 50\% active solids dissolved in a mixture of water and isopropanol. Both surfactin and the industrial surfactants are characterized by high surface activities, Table 1.

In this work, the use of surfactant solutions (e.g., surfactin $\left.+\mathrm{CH}_{3} \mathrm{OH} / \mathrm{H}_{2} \mathrm{O} ; 1: 1\right)$ as DESI spray solvents are observed to improve ionization of both hydrophobic and hydrophilic compounds. The surfactant solutions are applied to the analysis of food chemicals, peptides, pharmaceuticals and drugs of abuse. Signals more than an order of magnitude higher than those recorded using the standard $\mathrm{CH}_{3} \mathrm{OH} / \mathrm{H}_{2} \mathrm{O}$ (1:1) spray solvent are observed with this type of spray solvent system. As will be shown, the increased signals are mainly attributed to the production of smaller droplets, which is characterized by large sampling area and rapid ion evaporation.

\section{Experimental}

\section{Chemicals and Reagents}

Agrochemicals were purchased from Dr. Ehrenstorfer $\mathrm{GmbH}$. (Augsburg, Germany) and from Riedel de Haen, Pestanal quality (Seelze, Germany). The sudan dyes (I, II, III, and IV) and surfactin were purchased from Sigma-Aldrich (St. Louis, MO, USA). Fluorad FC-129, FC-135, and FC-171, 50\% active, were purchased from 3M (St. Paul, MN, USA). Stock solutions of simazine, enrofloxacin, ciprofloxacin, trifluralin, norfloxacin, oxytetracycline, bitertanol, and the sudan dyes (200-300 mg/L) were prepared in methanol and stored at $-20^{\circ} \mathrm{C}$. A stock solution $(3 \mathrm{mM})$ of surfactin was prepared in methanol, and $\mu \mathrm{M}$ working solutions were made with methanol/water (1:1). The industrial surfactants FC 129, FC-135, and FC-171 were diluted with $\mathrm{MeOH} / \mathrm{H}_{2} \mathrm{O}(1: 1)$ so that their surface tensions were comparable to each other and to the surfactin-containing spray. Melamine was purchased from TCI America (Portland, OR, USA), 2,4,6-trinitrotoluene standard

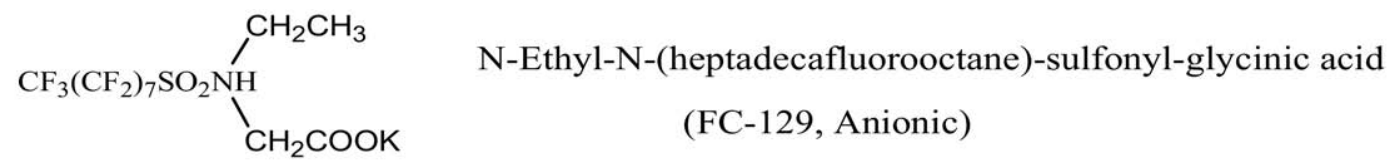

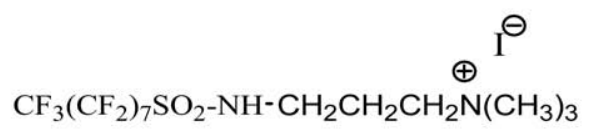

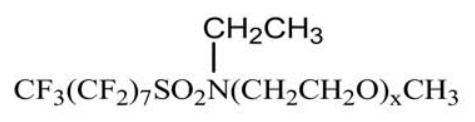

N-Propyl-N-(heptadecafluorooctane)-sulfonyl-N,N,N-trimethyl ammonium iodide (FC-135, Cationic)

$5,5,6,6,7,7,8,8,9,9,10,10,11,11,12,12,12$-Heptadecafluorodecane sulfonylamido polyethoxylate methyl ether (FC-171, Nonionic)

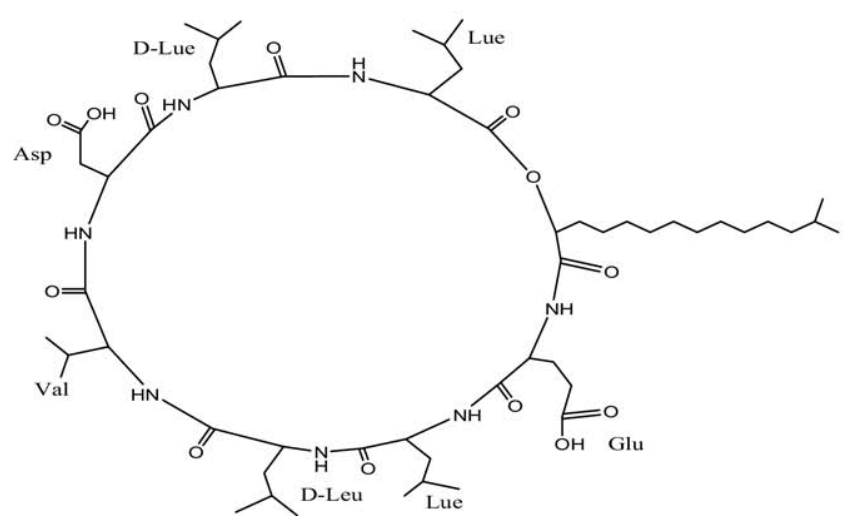

Surfactin (Anionic)

Scheme 1. Surfactants employed in DESI. 
Table 1. Surface tension of water as a function of surfactant concentration

\begin{tabular}{lcc}
\hline Surfactant & $\begin{array}{c}\text { Concentration } \\
(\mu \mathrm{M})\end{array}$ & $\begin{array}{c}\text { Surface Tension in water, } \\
25^{\circ} \mathrm{C}(\mathrm{mN} / \mathrm{m})^{\mathrm{a}}\end{array}$ \\
\hline \hline- & Pure water & 72 \\
Surfactin & 20.0 & 27 \\
FC-129 & 160.5 & 23 \\
FC-135 & 13.1 & 28 \\
FC-171 & - & 22 \\
\hline
\end{tabular}

a Surface tension in water obtained from references [35] for surfactin and [36] for FC-129, 135, and 171.

${ }^{\mathrm{b}} \mathrm{FC}-171$ is a polymer as indicated in scheme 1 and so its concentration is better given in wt/vol\%. Surface tension of a polymer solution consisting of $0.01 \mathrm{~g}$ solid dissolved in $100 \mathrm{~mL}$ of water is $22 \mathrm{mN} / \mathrm{m}$.

was procured from AccuStandard Inc. (New Haven, CT, USA), bradykinin and Substance $P$ were purchased from Sigma-Aldrich (St. Louis, MO, USA) and angiotensin II was purchased from Anaspaz Inc. (San Jose, CA, USA). Drug standards (Quikchek) were obtained from Alltech Applied Science Lab (State College, PA, USA), and Cerilliant from (Roundrock, TX, USA). HPLC grade methanol was obtained from Mallinckrodt Baker Inc. (Phillipsburg, NJ, USA). The surfaces used in this study included brown Kraft envelope paper, Whatman no. 1 filter paper (Maidstone, UK) and smooth Teflon (polytetrafluoroethylene, PTFE), Small Parts, Inc. (Miami Lakes, FL, USA). Spot sizes were measured from the wetted area when the spray was directed at water-sensitive Tee Jet paper (Wheaton, IL, USA).

\section{DESI Source and Mass Spectrometer}

Experiments were performed using a Thermo LTQ linear ion trap mass spectrometer (Thermo Scientific, San Jose, CA, USA) tuned for optimum detection of the precursor ion of interest. The instrument was set to collect spectra in the automatic gain control (AGC) mode for a maximum ion trap injection time of $100 \mathrm{~ms}$ using three microscans per spectrum. All DESI experiments were carried out using an OmniSpray ion source from Prosolia, Inc. (Indianapolis, IN, USA). This DESI source was fitted with a sample platform, X-Y-Z positioners, and a charge-coupled device (CCD) camera to allow precise positioning and to maintain positional accuracy. The main experimental parameters used were as follows: solvent flow rate, $3-5 \mu \mathrm{L} \mathrm{min}^{-1}$; spray voltage, $\pm 4-5 \mathrm{kV}$; capillary temperature, $150{ }^{\circ} \mathrm{C}$; tube lens (V), $\pm 65 \mathrm{~V}$; capillary voltage, $\pm 15 \mathrm{~V}$. DESI-MS parameters were as follows: spray angle, $55^{\circ}$; nitrogen gas pressure, $150 \mathrm{psi}$; distance from sample to tip, 5 $\mathrm{mm}$; distance from sample to inlet capillary, $1.5 \mathrm{~mm}$. A standard solvent spray of methanol/water (1:1) and methanol/water (1:1) doped with surfactants was used. An aliquot of $2.0 \mu \mathrm{L}$ of each sample solution was pipetted onto the surface. Tandem mass spectrometry experiments were performed using collision-induced dissociation (CID) with an isolation window of between $1.0-1.5(\mathrm{~m} / \mathrm{z}$ units, full width) and a collision energy of 25\%-35\% (manufacturer's unit).

\section{Results and Discussion}

\section{Evaluation of Effects of Surfactants}

To evaluate the contributions of surfactant to DESI mass spectra, a blank polytetrafluoroethylene substrate was examined using $1.0 \mu \mathrm{M}$ solution of surfactin in $\mathrm{MeOH} /$ $\mathrm{H}_{2} \mathrm{O}(1: 1)$ spray solvent in both the positive and in the negative ion modes (Figure 1). Surfactin ionizes readily in the negative ion mode and is therefore less useful as a spray solvent; in the positive mode it forms sodiated ions, which are barely observed (data not shown) under the concentrations used in this experiment. The industrial surfactants FC-129 and FC-135 give strong signals in the negative and the positive ion modes, respectively. The non-ionic polymer FC-171 is not useful in either polarity as a DESI spray solvent since it forms both positive and negative ion clusters covering most of the mass range of interest. For reasons that will become apparent, higher concentrations of the surfactants could not be used because they yielded complex background signals, contaminated the instrument, which was difficult to clean after experiments, or depleted the sample too quickly. With the wide variety of surfactants commercially available, one can prepare a surfactant solution containing either cationic, anionic or nonionic solutes that will not themselves ionize efficiently in the desired mode of operation (i.e., positive or negative mode) and so achieve low background and also efficient sample ionization.

To test the performance of surfactant-containing spray in DESI, first, two different drug mixtures were analyzed using surfactin spray and compared with the standard methanol/water, (1:1) spray solution. As can be seen from Figure 2, the surfactin-containing spray registered higher

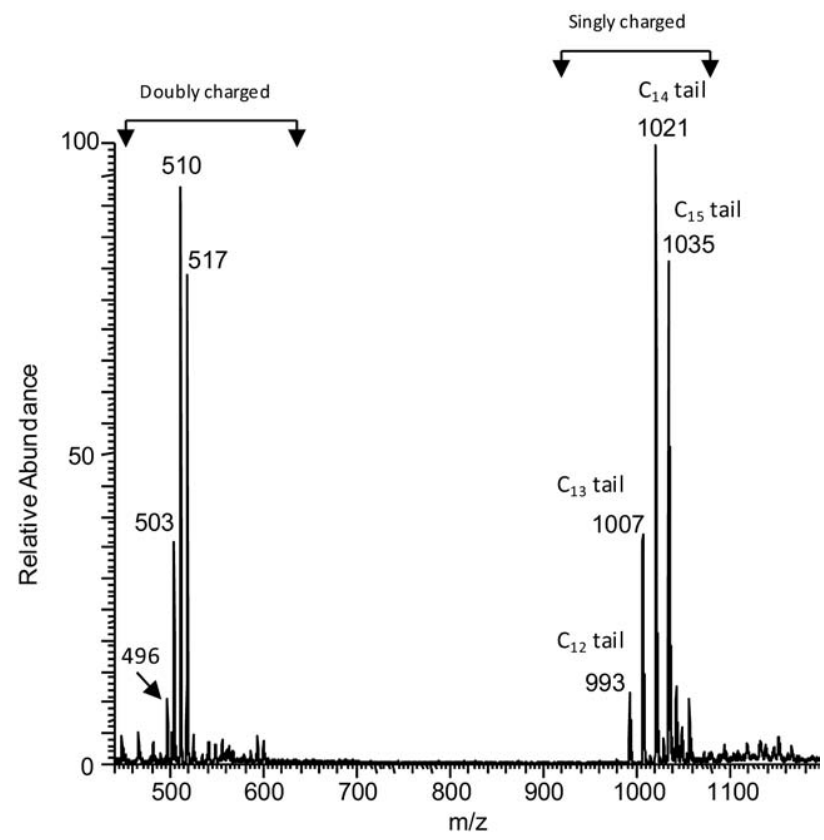

Figure 1. Blank DESI mass spectrum of $1.0 \mu \mathrm{M}$ surfactin spray solution from polytetrafluoroethylene (Teflon) substrate; negative ion mode. 


\section{Opiate Mixture $0.2 \mathrm{ng}$}
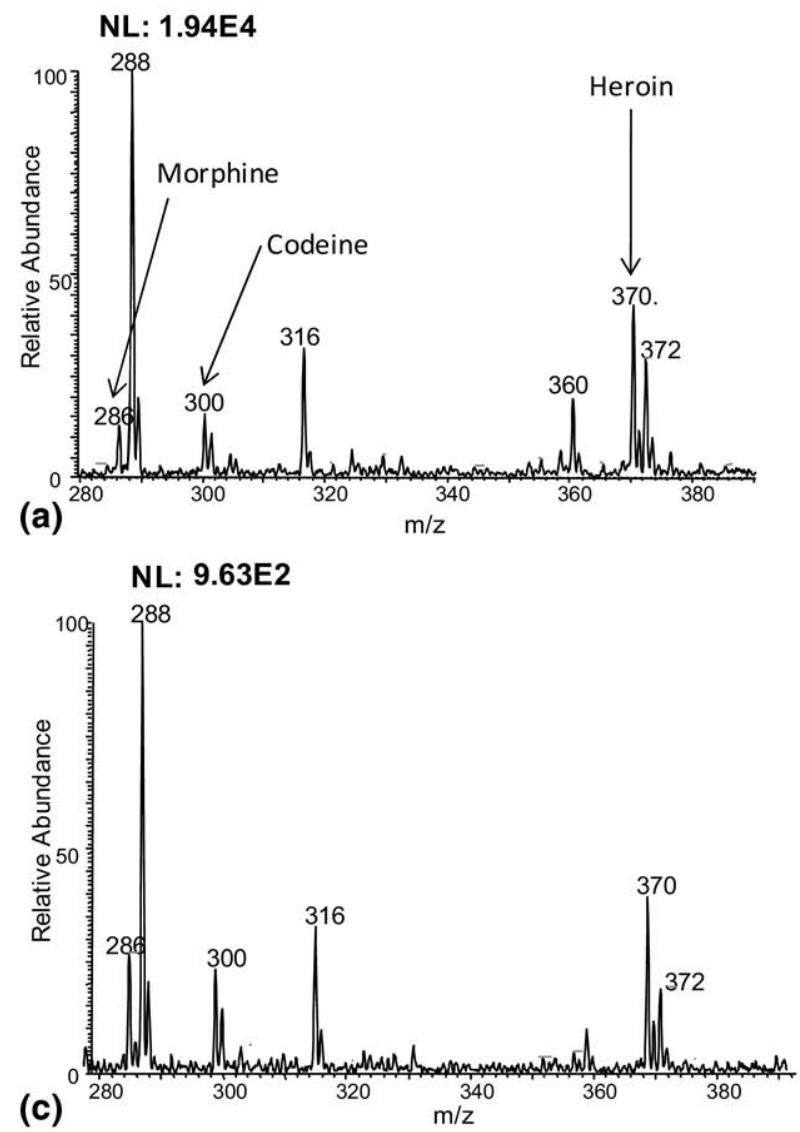

\section{Miscellaneous Mixture $1.0 \mathrm{ng}$}

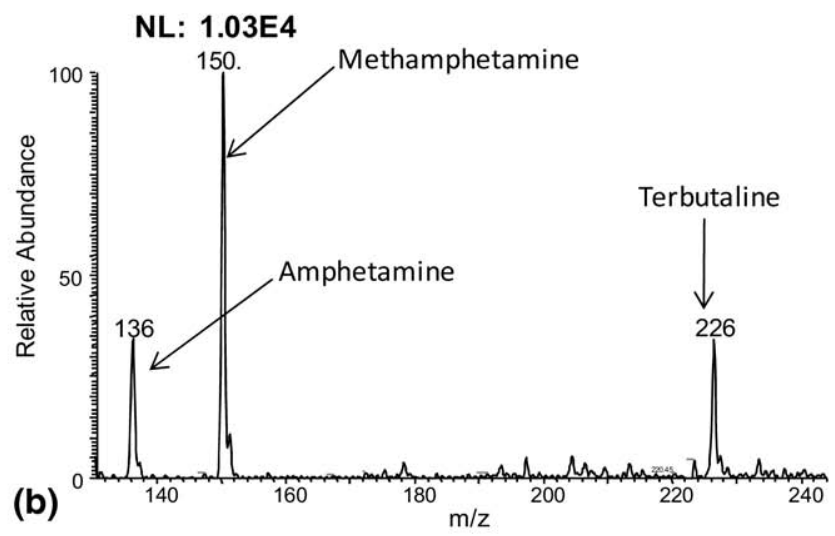

NL: 1.77E3

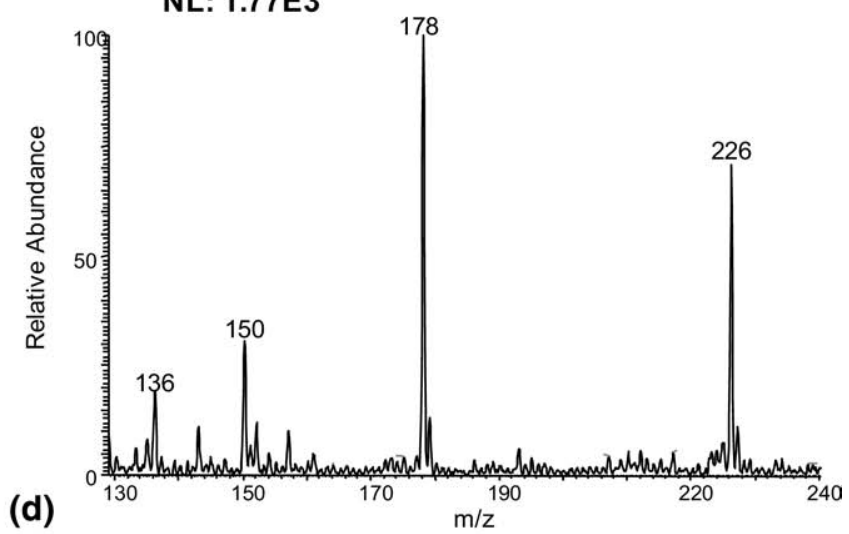

Figure 2. Positive ion DESI mass spectra recorded using surfactant spray solution compared with standard $\mathrm{MeOH} / \mathrm{H}_{2} \mathrm{O}$. (a) $0.2 \mathrm{ng}$ opiate mixture using $1.0 \mu \mathrm{M}$ surfactin solution, (b) $1.0 \mathrm{ng}$ miscellaneous drug mixture using $1.0 \mu \mathrm{M}$ surfactin solution, (c) $0.2 \mathrm{ng}$ opiate mixture using methanol/water, 1:1 with no added surfactin, and (d) $1.0 \mathrm{ng}$ miscellaneous drug mixture using methanol/water, 1:1 with no added surfactin. All samples were examined from smooth Teflon substrate. Ion intensity obtained using surfactin-containing spray is an order of magnitude higher than that derived from methanol/water spray solvent for a giving drug mixture. Ion intensity is shown as counts (NL).

ion intensity (an order of magnitude higher) for the analysis of both mixtures. This performance is typical for many water-soluble compounds analyzed in this work. Detection limits (LOD) of selected drugs using $1.0 \mu \mathrm{M}$ surfactin solution are listed in Table 2 and compared with the LOD of the standard $\mathrm{MeOH} / \mathrm{H}_{2} \mathrm{O}$ spray solvent. DESI MS/MS data on these compounds ionized using the surfactin-containing spray give the characteristic fragments indicated in Table 2. DESI spectra of sub-nanogram quantities of similar drugs have been reported using a

Table 2. LOD of some select pharmaceuticals and drugs of abuse using $1.0 \mu \mathrm{M}$ surfactin solution in $\mathrm{MeOH} / \mathrm{H}_{2} \mathrm{O}$ from Teflon surface

\begin{tabular}{|c|c|c|c|c|}
\hline \multirow[b]{2}{*}{ Drug compound } & \multirow[b]{2}{*}{ Molecular ion $[\mathrm{M}+\mathrm{H}]^{+}$} & \multirow[b]{2}{*}{ MS/MS transitions observed } & \multicolumn{2}{|c|}{$\operatorname{LOD}(p g)^{a}$} \\
\hline & & & $\mu \mathrm{M}$ surfactin & Standard $\mathrm{MeOH} / \mathrm{H}_{2} \mathrm{O}$ \\
\hline Terbutaline & 226 & $226 \rightarrow 152,170,208$ & 1 & 600 \\
\hline Benzoylecgonine & 290 & $290 \rightarrow 168,150,272,124$ & 1 & 400 \\
\hline Morphine & 286 & $286 \rightarrow 201,229,211,173,183$ & 15 & 30 \\
\hline Amphetamine & 136 & $136 \rightarrow 105,119,91,121$ & 20 & 600 \\
\hline Codeine & 300 & $300 \rightarrow 215,225,243,282,183$ & 15 & 30 \\
\hline Heroin & 370 & $370 \rightarrow 268,328,310,211,237$ & 1 & 3 \\
\hline
\end{tabular}

aLODs of all other analytes were obtained through MS/MS mode. 
standard $\mathrm{MeOH} / \mathrm{H}_{2} \mathrm{O}$ spray solution in a simple salt matrix [37] and the ion intensities were an order of magnitude lower than that obtained in this work when surfactin-containing spray was employed instead.

\section{Analysis of Hydrophobic Compounds}

To test if surfactant solutions are suitable for hydrophilic as well as hydrophobic compounds, a mixture consisting of two analytes in each category was examined by DESI using this spray solution. The two hydrophobic analytes, trifluralin and bitertanol, are not detected by DESI at sub-nanogram quantities when using the standard $\mathrm{CH}_{3} \mathrm{OH} / \mathrm{H}_{2} \mathrm{O}$ (1:1) spray solution. Compared with the standard methanol/water, 1:1 spray solution (Figure 3b) surfactin-containing spray (Figure 3a) performed far better in the analysis of trifluralin and bitertanol as well as the analysis of the two hydrophilic compounds, norfloxacin and oxytetracycline. Highly hydrophobic compounds such as trifluralin and bitertanol with large positive $\log \mathrm{K}_{\mathrm{ow}}$ values are generally insoluble in polar solvents; this makes their analysis with the standard $\mathrm{MeOH} / \mathrm{H}_{2} \mathrm{O}$ (1:1) spray solution difficult. Nonaqueous spray solvent, particularly $\mathrm{CH}_{3} \mathrm{CN} / \mathrm{CHCl}_{3}(1: 1)$, performed better in the analysis of similar hydrophobic compounds in terms of detection limits [23] but surfactant-containing spray gives similar intensities and a more stable signal.

\section{Applications to Food and Other Chemicals}

Rapid, in situ, and direct qualitative and quantitative analysis of agrochemicals in foodstuffs has recently been demonstrated using DESI [21]. Solvent optimization was important in this work. Using surfactant containing spray solutions, agrochemicals not previously analyzed successfully by DESI-MS were successfully ionized. These compounds included melamine, simazine, and the sudan dyes, as listed in Table 3. The detection limits of these hydrophobic compounds using $1.0 \mu \mathrm{M}$ surfactin are given in Table 3,
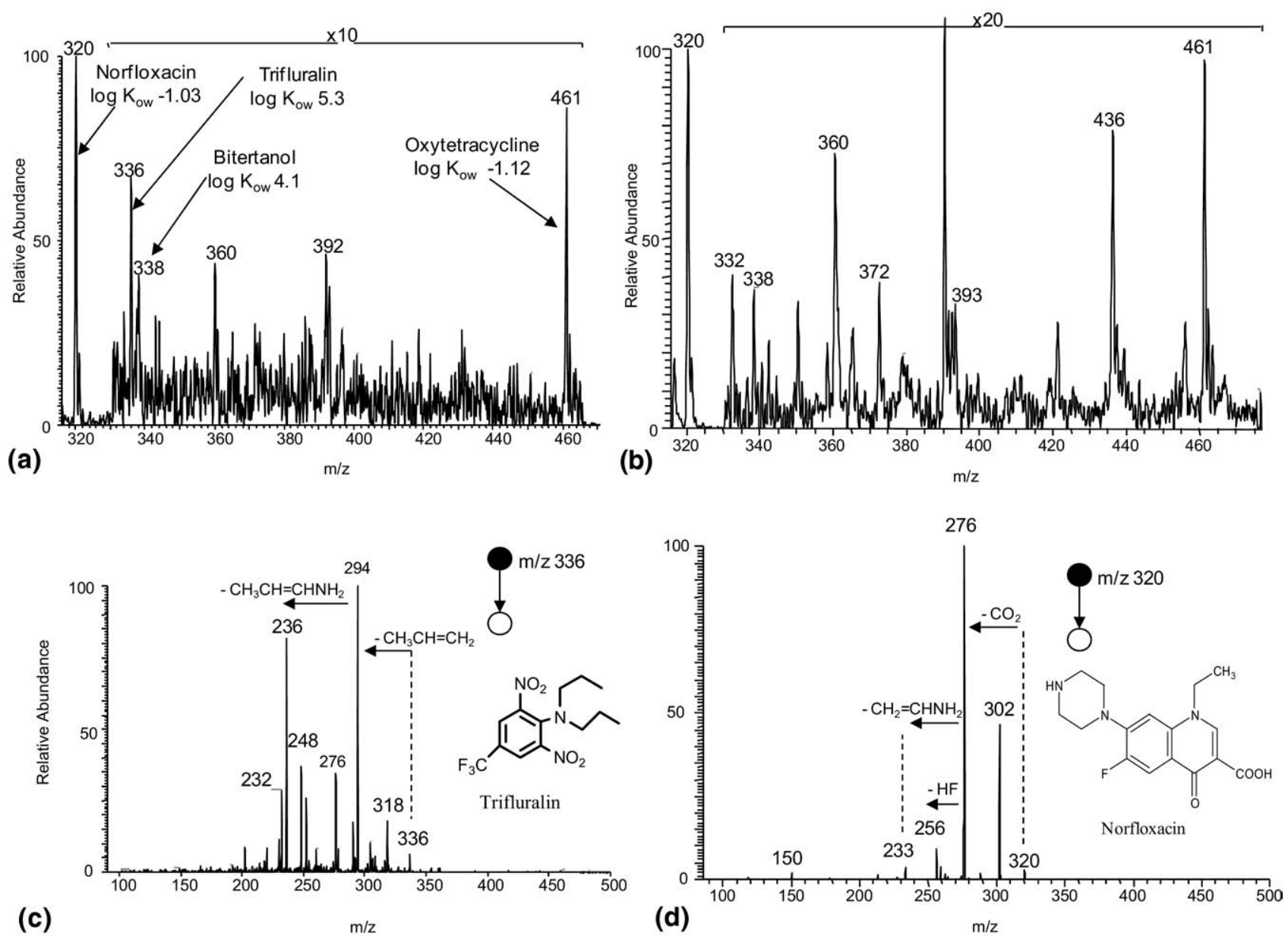

Figure 3. DESI-MS of hydrophobic (trifluralin and bitertanol) and hydrophilic (norfloxacin and oxytetracycline) compounds, $0.15 \mu$ g each. (a) $1.0 \mu \mathrm{M}$ surfactin solution in $\mathrm{MeOH} / \mathrm{H}_{2} \mathrm{O}$ (1:1). $\log \mathrm{K}_{\mathrm{ow}}$ values indicate hydrophobicity, higher values represent more hydrophobic compounds; (b) $\mathrm{MeOH}$ / $\mathrm{H}_{2} \mathrm{O}(1: 1)$ as the spray solvent without added surfactant. MS ${ }^{2}$ spectrum of (c) trifluralin and (d) norfloxacin in mixture when surfactant-containing spray was used. 
Table 3. Performance of surfactant spray solution compared with normal DESI spray of $\mathrm{MeOH} / \mathrm{H}_{2} \mathrm{O}$

\begin{tabular}{|c|c|c|c|c|c|}
\hline \multirow[b]{3}{*}{ Analyte } & \multirow[b]{3}{*}{$\begin{array}{c}\text { Form of molecular } \\
\text { ion examined }\end{array}$} & \multicolumn{4}{|c|}{ DESI method LOD $(\mathrm{pg})^{\mathrm{a}}$} \\
\hline & & \multirow{2}{*}{$\begin{array}{c}\text { Normal DESI } \\
(1: 1, \mathrm{vol} / \mathrm{vol}) \\
\mathrm{MeOH} / \mathrm{H}_{2} \mathrm{O} \\
\end{array}$} & \multicolumn{3}{|c|}{ Surfactant spray solutions } \\
\hline & & & $\begin{array}{c}1 \mu \mathrm{M} \\
\text { surfactin } \\
\end{array}$ & $\begin{array}{c}20 \mu \mathrm{M} \\
\text { surfactin } \\
\end{array}$ & $\begin{array}{l}10 \mu \mathrm{M} \\
\mathrm{FC}-135 \\
\end{array}$ \\
\hline \multicolumn{6}{|l|}{ Food chemicals } \\
\hline Melamine & {$[\mathrm{M}+\mathrm{H}]^{+}$} & 4000 & 2 & 4 & 200 \\
\hline Simazine & {$[\mathrm{M}+\mathrm{H}]^{+}$} & 2000 & 20 & 30 & 20 \\
\hline Sudan Dye I & {$[\mathrm{M}+\mathrm{H}]^{+}$} & $\mathrm{N} / \mathrm{A}$ & 2000 & 2000 & 300 \\
\hline Sudan Dyes II, III, \& IV & {$[\mathrm{M}+\mathrm{H}]^{+}$} & $\mathrm{N} / \mathrm{A}$ & 30 & 30 & 200 \\
\hline \multicolumn{6}{|l|}{ Peptides } \\
\hline Bradykinin & {$[\mathrm{M}+2 \mathrm{H}]^{2+}$} & 20 & - & - & 200 \\
\hline Substance $P$ & {$[\mathrm{M}+2 \mathrm{H}]^{2+}$} & 2000 & 2000 & 2000 & 2000 \\
\hline Angiotensin II & {$[\mathrm{M}+2 \mathrm{H}]^{2+}$} & 20 & 300 & - & 200 \\
\hline \multicolumn{6}{|l|}{ Miscellaneous } \\
\hline Trinitrotoluene & $\mathrm{M}^{-}$ & 10 & 2 & 2 & 3 \\
\hline Trifluralin & {$[\mathrm{M}+\mathrm{H}]^{+}$} & $\mathrm{N} / \mathrm{A}$ & 2000 & 2000 & 900 \\
\hline Nofloxacin & {$[\mathrm{M}+\mathrm{H}]^{+}$} & 20 & 2 & 3 & 1.5 \\
\hline Bitertanol & {$[\mathrm{M}+\mathrm{H}]^{+}$} & N/A & 600 & 4000 & 30 \\
\hline Oxytetracycline & {$[\mathrm{M}+\mathrm{H}]^{+}$} & $<1000$ & 100 & 400 & 90 \\
\hline Enrofloxacin/ciprofloxacin & {$[\mathrm{M}+\mathrm{H}]^{+}$} & 300 & 30 & 20 & 20 \\
\hline
\end{tabular}

${ }^{a}$ With the exception of the peptides, LODs of all other analytes were obtained through MS/MS mode. For surfactant spray solutions, mass spectrum of the analyte was recorded within the first few seconds of analyte sampling, consisting of at least $36 \mu$ scans. Each was repeated for more than three times. N/A = analyte could not be detected at $10 \mathrm{ng}$ quantities.

where they are compared with those recorded using other spray solutions.

Recent incidents of melamine food contamination have led to a search for rapid and sensitive methods for melamine analysis. A different ambient ionization method, low-temperature plasma (LTP) ionization [38] has been reported to be effective method but previous attempts at melamine analysis using DESI have not been successful. In this work, DESI also is demonstrated to be effective in melamine analysis (Table 3 ). Amounts as small as $2 \mathrm{pg}$ (e.g., $2 \mu \mathrm{L} \times 1 \mathrm{ppb}$ ) can be detected using $1.0 \mu \mathrm{M}$ surfactin solution. Although LTP allows efficient analysis of melamine in most complex matrices, heating to about $160{ }^{\circ} \mathrm{C}$ is required to reach the ultimate sensitivity. With DESI, melamine can be detected in matrices such as urine and serum without heating at sub- ppm concentrations. We have not succeeded, however, in detecting melamine in liquid milk by DESI.

Another analyte of interest, simazine, is currently classified by the EPA as a general use pesticide. However, its use to control algae in swimming pools, hot tubs, and whirlpools was canceled by the EPA in 1994, and it is suspected to cause breast cancer, and analytical methods for its detection at low concentrations are needed. Here, surfactin spray DESI is shown to be an efficient mass spectrometric method for simazine analysis at subpicogram quantities, Table 3 . Figure 4 shows the tandem MS of melamine and simazine near their detection limits using surfactin spray solution.

For particular analytes, all three surfactant-containing spray solutions give similar limits of detection (LODs) for the analysis of water-soluble hydrophilic analytes (Table
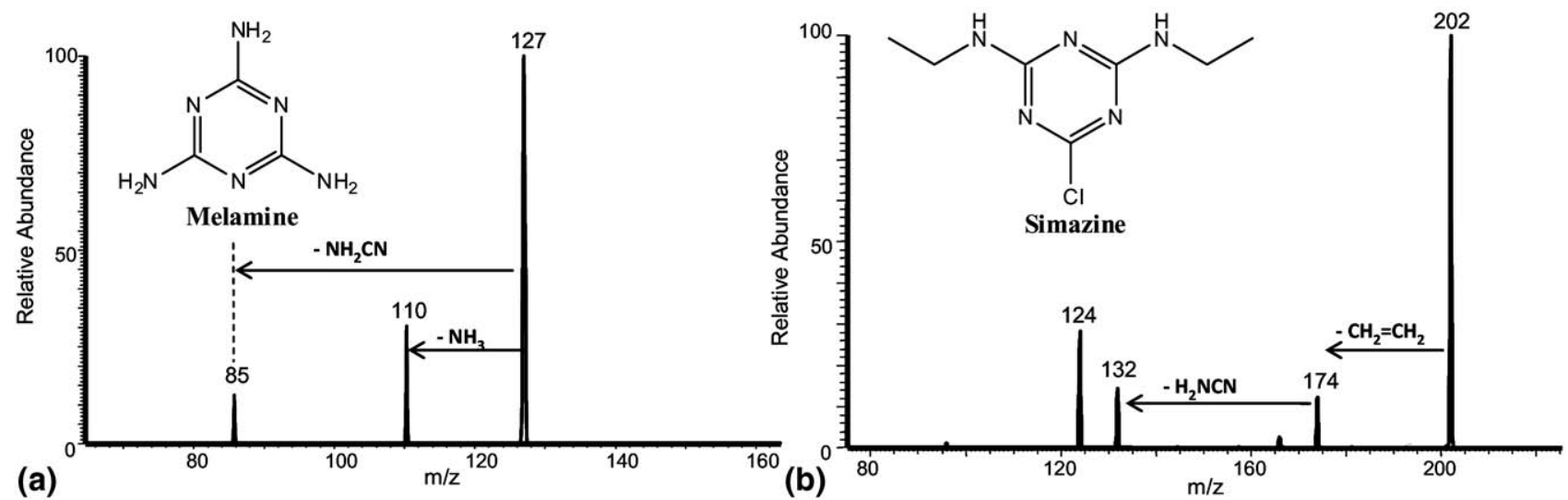

Figure 4. Positive ion mode DESI MS/MS recorded from Teflon using surfactin spray solution.

(a) 2 pg melamine and (b) $20 \mathrm{pg}$ simazine. 
3) regardless of the surface tension. Note that $20.0 \mu \mathrm{M}$ surfactin and 10.0 $\mu \mathrm{M}$ FC-135 have comparable surface tensions, Table 1. For water-insoluble hydrophobic analytes including the sudan dyes, bitertanol and trifluralin, small differences in LOD were observed when comparing different surfactant spray solutions. While this result is not understood in detail, FC-135 generally performed better than surfactin in the analysis of highly hydrophobic and non-volatile analytes. Increasing surfactant concentration did not offer any advantage in terms of detection limits.

The enhanced performance of the surfactant-containing spray is mainly attributed to the production of smaller primary droplets leading to increased rates of sample desorption as ions. This and other effects result from the manipulation of surface tension of the DESI spray solvent because of the added surface active, long-chain hydrophobic surfactants, and are discussed below.

\section{Surface Tension, Spot Size on Surface, and Droplet Size}

In an attempt to understand the sources of the enhanced ion intensities observed in this study, the sampling area covered by the primary microdroplets derived from different DESI spray solvents was measured using water sensitive paper in experiments performed at 5 $\mu \mathrm{L} /$ min solvent flow rates and a $\mathrm{N}_{2}$ pressure of 150 psi. An average sampling area of about $3.5 \mathrm{~mm}^{2}$ was measured for $1.0 \mu \mathrm{M}$ surfactin solution in $\mathrm{CH}_{3} \mathrm{OH} / \mathrm{H}_{2} \mathrm{O}$ versus $1.7 \mathrm{~mm}^{2}$ for the standard $\mathrm{CH}_{3} \mathrm{OH} / \mathrm{H}_{2} \mathrm{O}(1: 1)$ spray solvent containing no surfactin (Figures S1 and S2, Supporting Information, which can be found in the electronic version of this article).

The electrospray onset voltage $\left(\mathrm{V}_{\mathrm{on}}\right)$ is related to the capillary diameter and surface tension $(\gamma)$ of the spray solution according to eq 1 [39],

$$
\mathrm{V}_{\mathrm{on}}=2 \times 10^{5}\left(\gamma \cdot \mathrm{r}_{\mathrm{c}}\right)^{1 / 2}\left(4 \mathrm{~d} / \mathrm{r}_{\mathrm{c}}\right)
$$

where $r_{c}$ is the i.d. of the capillary and $d$ is the capillary-electrode distance. Since the surface tension of a liquid is directly related to the discharge onset voltage during electrospray, reduced surface tension due to the presence of surfactants can lead to the production of smaller primary droplets in DESI. The size and kinetic energy of the impacting primary droplets derived from $\mathrm{CH}_{3} \mathrm{OH} / \mathrm{H}_{2} \mathrm{O}(1: 1)$ spray solution has been measured as $3 \mu \mathrm{m}$ and $500 \mathrm{MeV}$ respectively [26]. Primary droplets derived from surfactant-containing spray solution are expected to be smaller than these. As a result of their smaller size they will disperse more giving rise to the observed larger spray spot on the surface. The reduced contact angle that results when surface tension of a liquid is reduced [40] will also play a role in increasing the spot size when the liquid contacts the surface, thereby providing a larger sampling area.

The images of secondary droplets produced upon impact of different surfactant spray solutions were captured by using water sensitive paper, set orthogonal to the DESI substrate (smooth Teflon) to investigate the effect of surface tension on droplet size. The results (Figure S3, Supporting Information) indicate that at high surfactant concentrations, the secondary droplets leaving the DESI surface are much smaller than is the case for low concentrations; they become so small at high concentrations that they cannot be detected by the water sensitive paper although a mass spectrum can still be measured. Thus, the production of smaller primary droplets not only yields larger sampling area but also produces smaller secondary microdroplets that are characterized by better ion evaporation efficiencies.

\section{Temporal Response}

Figure 5 shows the total ion current (TIC) for methylene blue recorded in a DESI experiment using $\mathrm{CH}_{3} \mathrm{OH}$ / $\mathrm{H}_{2} \mathrm{O}(1: 1)$ compared with that recorded using 1.0 and 10 $\mu \mathrm{M}$ surfactin spray solutions. The signal of surfactant spray solution rises rapidly at the onset of the spray process (although the $1.0 \mu \mathrm{M}$ data is noisy) and drops exponentially. The rapid rise and especially the high absolute signal reached might be because the sample is easier to dissolve in the surfactant spray solution due to the increased solubilizing power and greater wetting property of the spray solution. The low surface tension suggests that the spray will spread out more quickly on the surface and dissolve the analyte from a larger area. In the case of the standard $\mathrm{CH}_{3} \mathrm{OH} / \mathrm{H}_{2} \mathrm{O}$ spray solution, the maximum signal is obtained after some delay (Figure 5), analyte apparently taking longer to dissolve in the charged droplet consisting of only methanol/water, 1:1. This delay has been measured previously and attributed to the time required for dissolution of the analyte [41].

Increased surfactant concentration results in virtually instantaneous signal production, Figure 5b. For 10.0 $\mu \mathrm{M}$ surfactin solution, the signal lasted for only $4 \mathrm{~s}$ compared with $12 \mathrm{~s}$ for $1.0 \mu \mathrm{M}$. The advantage of the shorter time is that the mass spectrometer can be operated at a higher repetition rate (in this work, three $\mu$ scans were acquired per spectrum with the time per spectrum being $300 \mathrm{~ms}$ including an ion injection time of $100 \mathrm{~ms}$ ). The $4 \mathrm{~s}$ of signal allowed about $120 \mu$ scans to be recorded, yielding some 42 mass spectra. Examples of mass spectra using 0.0,1.0 and $10.0 \mu \mathrm{M}$ surfactin spray solutions, obtained by integrating data over $2 \mathrm{~s}$ are provided in Figure S4 (Supporting Information) and show that ion intensity increases with surfactant concentration within this analysis time (Figure S5, Supporting Information).

\section{Preconcentration of Analyte at Surface}

DESI spray solvents doped with micromolar solutions of simple inorganic salts like sodium chloride show increased ion intensities of the protonated species (Figure S6, Supporting Information). Preconcentration of analyte at the surface as a result of salting out during 
$1.0 \mu \mathrm{M}$ surfactin

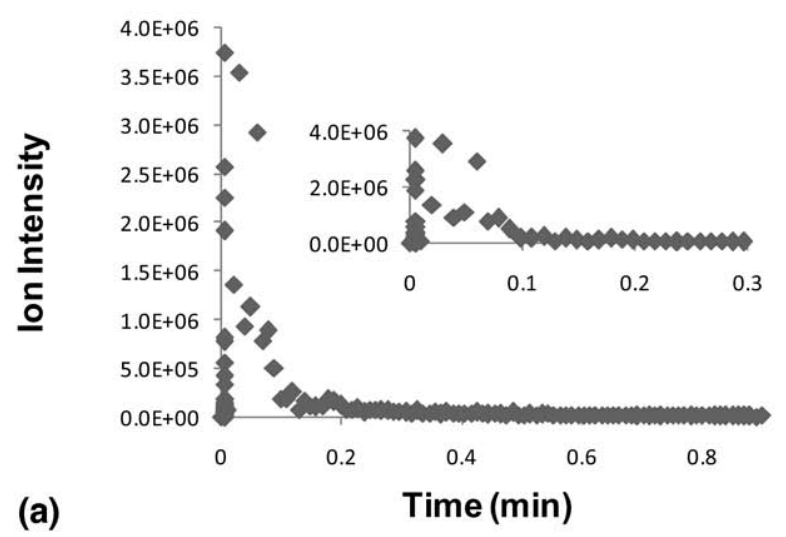

$10.0 \mu \mathrm{M}$ surfactin

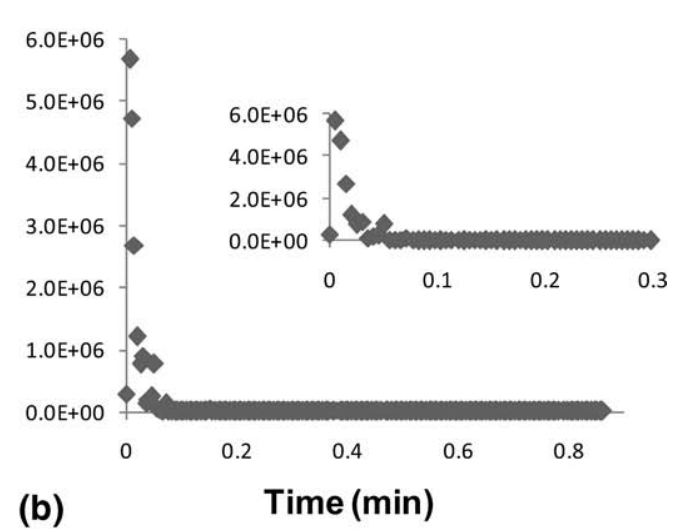

$\mathrm{MeOH} / \mathrm{H}_{2} \mathrm{O}(1: 1)$

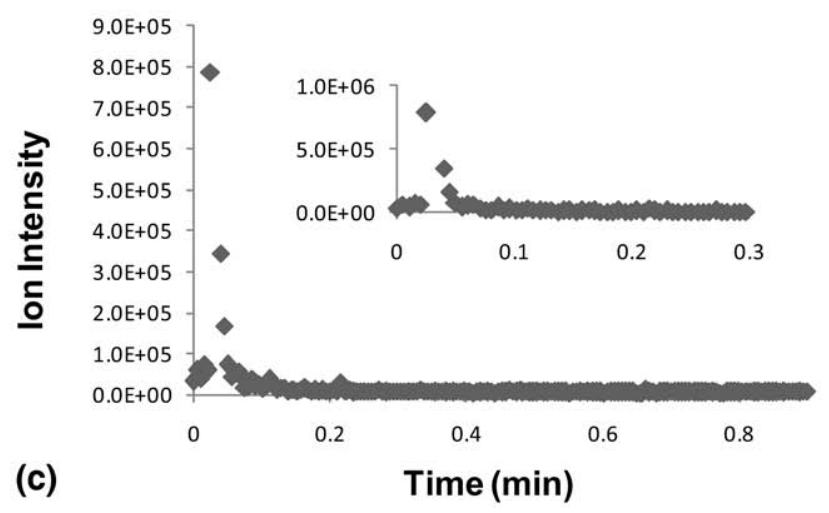

Figure 5. Plot of the total ion current (TIC) for $20 \mathrm{ng}$ of methylene blue sampled by DESI from a Teflon substrate. (a) $1.0 \mu \mathrm{M}$ surfactin spray, (b) $10.0 \mu \mathrm{M}$ surfactin spray, and (c) methanol/water (1:1) solution without added surfactant.

the spray process is believed to be responsible. A related surface effect is believed to be responsible for a very large gain in signal intensity observed when long-chain primary alkyl amines are added to the spray solution [42]. Although this ion enhancement is attributed to post-desorption effects such as enhancement of ion evaporation due to the presence of the hydrophobic alkyl amine ligands, it is suggested that preconcentration of the analyte at the surface during the impact of the spray solution might also contribute to the intensity gain. The use of long-chain hydrophobic surfactants in DESI is expected and found (Figure S7, Supporting Information) to have similar effects at the low concentrations tested. Competition between hydrophobic analytes and surfactants for surface sites can complicate these effects.

\section{Conclusions}

This study shows that an increase in desorption ionization signals of more than an order of magnitude is achieved for all small organic molecules tested in this study when a spray solution containing $\mu \mathrm{M}$ surfactant is used. Unlike reactive DESI, in which reagents are added to the spray solvent to enhance signals for specific analytes by an appropriate chemical reaction, surfactant-containing spray solutions function by manipulating the physical properties of the spray solution, specifically the surface tension, so enhancing the ion yields of most analytes. Four properties of the spray are thought to be affected by the change in surface tension: (1) size of droplets, (2) sampling area, (3) surface wettability, and (4) solubilizing power. The enhanced ion signals observed are mainly attributed to the production of smaller droplets, which spread to cover a larger surface area; better ion evaporation, enhanced proton transfer efficiencies, and the greater solubilizing power of the solution may all play roles. Enhanced rates of desorption were also observed with the surfactantcontaining spray solutions, and this might be responsible for the observed improvement of ionization efficiency per unit time measured in the temporal profiles. Non-aqueous spray solvents are known to deposit less internal energy than methanol/water, a result that is explained by solvent effects on surface tension. Modification of the surface tension has been achieved much more effectively in this study by adding surfactant, with the resulting observed large effects on ion signal intensity, with smaller ion internal energy deposition as well 
(Figure S8, Supporting Information). High throughput analysis is also facilitated by the addition of the surfactant with almost instantaneous appearance of DESI signals. Indirectly, the work provides support for the standard DESI mechanism, where initially arriving droplets create a liquid thin film to dissolve the analytes present on the surface, and subsequent droplet-liquid thin film collisions produce secondary droplets containing the analyte.

\section{Acknowledgments}

The authors acknowledge support for this work by the National Science Foundation (NSF0848650), Office of Naval Research (N00014-05-1-0454), and Thermo Fisher Scientific (1320036659).

\section{Appendix A Supplementary Material}

Supplementary material associated with this article may be found in the online version at doi:10.1016/ j.jasms.2010.04.001.

\section{References}

1. Takats, Z.; Wiseman, J. M.; Gologan, B.; Cooks, R. G. Mass Spectrometry Sampling Under Ambient Conditions with Desorption Electrospray Ionization. Science 2004, 306, 471-473.

2. Takats, Z.; Wiseman, J. M.; Cooks, R. G. Ambient Mass Spectrometry Using Desorption Electrospray Ionization (DESI): Instrumentation, Mechanisms, and Applications in Forensics, Chemistry, and Biology. J. Mass Spectrom. 2005, 40(10), 1261-1275.

3. Na, N.; Zhao, M.; Zhang, S.; Yang, C.; Zhang, X. Development of a Dielectric Barrier Discharge Ion Source for Ambient Mass Spectrometry. J. Am. Soc. Mass Spectrom. 2007, 18, 1859-1862.

4. Harris, G. A.; Nyadong, L.; Fernandez, F. M. Recent Developments in Ambient Ionization Techniques for Analytical Mass Spectrometry. Analyst 2008, 133, 1297-1301.

5. Cody, R. B.; Laramee, J. A.; Durst, H. D. Versatile New Ion Source for the Analysis of Materials in Open Air under Ambient Conditions. Anal. Chem. 2005, 77(8), 2297-2302.

6. Ford, M. J.; Van Berkel, G. J. An Improved Thin-Layer Chromatography/Mass Spectrometry Coupling Using a Surface Sampling Probe Electrospray Ion Trap System. Rapid Commun. Mass Spectrom. 2004, 18(12), 1303-1309.

7. McEwen, C. N.; McKay, R. G.; Larsen, B. S. Analysis of Solids, Liquids, and Biological Tissues Using Solids Probe Introduction at Atmospheric Pressure on Commercial LC/MS Instruments. Anal. Chem. 2005, 77(23), 7826-7831.

8. Shiea, J.; Huang, M. Z.; Hsu, H. J.; Lee, C. Y.; Yuan, C. H.; Beech, I.; Sunner, J. Electrospray-Assisted Laser Desorption Ionization Mass Spectrometry for Direct Ambient Analysis of Solids. Rapid Commun. Mass Spectrom. 2005, 19(24), 3701-3704.

9. Kauppila, T. J.; Talaty, N.; Salo, P. K.; Kotiaho, T.; Kostiainen, R.; Cooks, R. G. New Surfaces for Desorption Electrospray Ionization Mass Spectrometry: Porous Silicon and Ultra-Thin Layer Chromatography Plates. Rapid Commun. Mass Spectrom. 2006, 20(14), 2143-2150.

10. Van Berkel, G. J.; Tomkins, B. A.; Kertesz, V. Thin-Layer Chromatography/Desorption Electrospray Ionization Mass Spectrometry: Investigation of Goldenseal Alkaloids. Anal. Chem. 2007, 79(7), 2778-2789.

11. Williams, J. P.; Patel, V. J.; Holland, R.; Scrivens, J. H. The Use of Recently Described Ionization Techniques for the Rapid Analysis of Some Common Drugs and Samples of Biological Origin. Rapid Commun. Mass Spectrom. 2006, 20(9), 1447-1456.

12. Leuthold, L. A.; Mandscheff, J.; Fathi, M.; Giroud, C.; Augsburger, M.; Varesio, E.; Hopfgartner, G. Desorption Electrospray Ionization Mass Spectrometry: Direct Toxicological Screening and Analysis of Illicit Ecstasy Tablets. Rapid Commun. Mass Spectrom. 2006, 20(2), 103-110.

13. Ifa, D. R.; Manicke, N. E.; Dill, A. L.; Cooks, R. G. Latent Fingerprint Chemical Imaging by Mass Spectrometry. Science 2008, 321(5890), 805.

14. Rubakhin, S. S.; Jurchen, J. C.; Monroe, E. B.; Sweedler, J. V. Imaging Mass Spectrometry: Fundamentals and Applications to Drug Discovery. Drug Disc. Today 2005, 10(12), 823-837.
15. Esquenazi, E.; Dorrestein, P. C.; Gerwick, W. H. Probing Marine Natural Product Defenses with DESI-Imaging Mass Spectrometry. PNAS 2009 106(18), 7269-7270.

16. Kertesz, V.; Van Berkel, G. J. Scanning and Surface Alignment Considerations in Chemical Imaging with Desorption Electrospray Mass Spectrometry. Anal. Chem. 2008, 80(4), 1027-1032.

17. Wiseman, J. M.; Ifa, D. R.; Zhu, Y.; Manicke, N. E., Kissinger, P. T. Cooks, R. G. Desorption Electrospray Ionization Mass Spectrometry: Imaging Drugs and Metabolites in Tissues. PNAS 2008, 105(47), 18120 18125.

18. Ifa, D. R.; Gumaelius, L. M.; Eberlin, L. S.; Manicke, N. E.; Cooks, R. G. Forensic Analysis of Inks by Imaging Desorption Electrospray Ionization (DESI) Mass Spectrometry. Analyst 2007, 132, 461-467.

19. Ifa, D. R.; Jackson, A. U.; Paglia, G.; Cooks, R. G. Forensic Applications of Ambient Ionization Mass Spectrometry. Anal. Bioanal. Chem. 2009, 394(8), 1995-2008.

20. Li, M.; Chen, H.; Wang, B.; Yang, X.; Lian, J.; Chen, J. Direct Quantification of PAHs in Biomass Burning Aerosols by Desorption Electrospray Ionization Mass Spectrometry. Int. J. Mass Spectrom. 2009, 281(1/2), 31-36.

21. Garci'a-Reyes, J. F.; Jackson, A. U.; Molina-Di'az, A.; Cooks, R. G. Desorption Electrospray Ionization Mass Spectrometry for Trace Analysis of Agrochemicals in Food. Anal. Chem. 2009, 81 (2), 820-829.

22. Chen, H.; Talaty, N. N.; Takáts, Z.; Cooks, R. G. Desorption Electrospray Ionization Mass Spectrometry for High-Throughput Analysis of Pharmaceutical Samples in the Ambient Environment. Anal. Chem. 2005, 77(21), 6915-6927.

23. Badu-Tawiah, A.; Bland, C.; Campbell, I. D.; Cooks, R. G. Non-aqueous Spray Solvents and Solubility Effects in Desorption Electrospray Ionization J. Am. Soc. Mass Spectrom. 2010, 21, 572-579.

24. Wu, C.; Ifa, D. R.; Manicke, N. E.; Cooks, R. G. Rapid, Direct Analysis of Cholesterol by Charge Labeling in Reactive Desorption Electrospray Ionization Anal. Chem. 2009, 81(18), 7618-7624.

25. Costa, A. B.; Cooks, R. G. Simulated Splashes: Elucidating the Mechanism of Desorption Electrospray Ionization Mass Spectrometry. Chem. Phys. Lett. 2008, 464(1/3), 1-8.

26. Venter, A.; Sojka, P. E.; Cooks, R. G. Droplet Dynamics and Ionization Mechanisms in Desorption Electrospray Ionization Mass Spectrometry. Anal. Chem. 2006, 78(24), 8549-8555.

27. Vincenti, M.; Cooks, R. G. Desorption Due to Charge Exchange in Low-Energy Collisions of Organofluorine Ions at Solid Surfaces. Org. Mass Spectrom. 1988, 23(5), 317.

28. Volny, M.; Venter, A.; Smith, S. A.; Pazzi, M.; Cooks R. G. Surface Effects and Electrochemical Cell Capacitance in Desorption Electrospray Ionization. Analyst 2008, 133, 525-531.

29. Manicke, N. E.; Wiseman, J. M.; Ifa, D. R.; Cooks, R. G. Desorption Electrospray Ionization (DESI) Mass Spectrometry and Tandem Mass Spectrometry (MS/MS) of Phospholipids and Sphingolipids: Ionization, Adduct Formation, and Fragmentation. J. Am. Soc. Mass Spectrom. 2008, 19, 531-543.

30. Loriau, M.; Alves, S.; Churlaud, F.; Tabet, J.-C. Solvent Effects on the DESI Mass Spectra of Industrial Polymers and Additive. Proceedings of the ASMS, Philadelphia, PA, 2009.

31. Hagan, N. A.; Cornish, T. J.; Pilato, R. S.; Van Houten, K. A.; Antoine M. D.; Lippa, T. P.; Becknell, A. F.; Demirev, P. A. Detection and Identification of Immobilized Low-Volatility Organophosphates by Desorption Ionization Mass Spectrometry. Int. I Mass Spectrom. 2008 $278(2 / 3), 158-165$

32. Sparrapan, R.; Ebelin, L. S.; Haddad, R.; Cooks, R. G.; Ebelin, M. N. Augusti, R. Ambient Eberlin Reactions Via Desorption Electrospray Ionization Mass Spectrometry. J. Mass Spectrom. 2006, 41(9), 1242-1264.

33. Huang, G.; Chen, H.; Zhang, X. Cooks, R. G.; Ouyang, Z. Rapid Screening of Anabolic Steroids in Urine by Reactive Desorption Electrospray Ionization. Anal. Chem. 2007, 79(21), 8327-8332.

34. Nicolas, J. P. Molecular Dynamics Simulation of Surfactin Molecules at the Water-Hexane Interface. Biophys. I. 2003, 85, 1377-1391.

35. Ishigami, Y.; Osman, M.; Nakahara, H.; Sano, Y.; Ishiguro, R.; Matsumoto, M. Significance of b-Sheet Formation for Micelization and Surface Adsorption of Surfactin. Coll. Surf. B Biointer. 1995, 4, 341-348.

36. Kissa, E. Fluorinated Surfactants and Repellents, 2nd ed.; Revised and Expanded. Surfactant Science, vol. 97; Marcel Dekker: NY, 2001; p. 350.

37. Jackson, A. U.; Talaty, N.; Cooks, R. G. Salt Tolerance of Desorption Electrospray Ionization (DESI). J. Am. Soc. Mass Spectrom. 2007, 18, $2218-2225$

38. Huang, G.; Ouyang, Z.; Cooks, R. G. High-Throughput Trace Melamine Analysis in Complex Mixtures. Chem. Commun. 2009, 556-558.

39. Cloupeau, M.; Prunet-Foch, B. Electrostatic Spraying of Liquids in Cone-Jet Mode. J. Electrost. 1989, 22(2), 135-159.

40. de Gennes, P. D. Wetting Statics and Dynamics. Rev. Mod. Phys. 1985, 57(3), 827-863.

41. Bereman, M. S.; Muddiman, D. C. Detection of Attomole Amounts of Analyte by Desorption Electrospray Ionization Mass Spectrometry (DESI-MS) Determined Using Fluorescence Spectroscopy. J. Am. Soc. Mass Spectrom. 2007, 18, 1093-1096.

42. Nyadong, L.; Green, M. D.; De Jesus, V. R.; Newton, P. N.; Fernández, F. M. Reactive Desorption Electrospray Ionization Linear Ion Trap Mass Spectrometry of Latest-Generation Counterfeit Antimalarials Via Noncovalent Complex Formation. Anal Chem. 2007, 79, 2150-2157. 